\title{
Viabilidade de implantação de tanques-rede no reservatório da PCH do estado do Tocantins, Brasil
}

Para que ocorra o desenvolvimento sustentável da piscicultura intensiva em reservatórios, é fundamental ter informações sobre as características limnológicas do corpo hídrico contribuinte, suas peculiaridades e capacidade de suporte. Portanto, o estudo teve como objetivo verificar a viabilidade de implantação de piscicultura intensiva em tanques-rede no reservatório da PCH Boa Sorte, Tocantins, avaliando os locais favoráveis para instalação de tanques-rede, as características limnológicas e a capacidade de suporte do corpo hídrico. O reservatório está localizado no rio Palmeiras que pertence à sub bacia do rio Palma e bacia Paranã, sendo este importante tributário da margem direita do rio Tocantins. Para identificar as áreas favoráveis à implantação do parque aquícola, fo analisada toda a área do reservatório, perfazendo uma área de 232 ha de lâmina d'água, onde a maior parte, 141 ha, foi considerada favorável. Em seguida, foram analisados os parâmetros limnológicos, a saber: Temperatura, pH, oxigênio dissolvido, transparência, clorofila-a, fósforo total, amônia, nitrito e nitrato. Todos os parâmetros, com exceção do fósforo total, atenderam aos valores preconizados na resolução ${ }^{\circ} 357$ do CONAMA (2005). A concentração média de fósforo total durante o período de estudo foi de 0,13 mg.L-1, o que demonstra que a capacidade de suporte do reservatório da PCH Boa Sorte já foi ultrapassada. Diante dos dados apresentados neste estudo, concluiu-se que o cultivo de peixes em tanques-rede no reservatório da PCH Boa Sorte não é recomendado, pois tal atividade pode agravar o processo de eutrofização existente no corpo hídrico em estudo.

Palavras-chave: Capacidade de suporte; Piscicultura; Reservatório; Tanques-rede.

\section{Feasibility of implantation of net tanks in the SHP reservoir in the state of Tocantins, Brazil}

\begin{abstract}
For the sustainable development of intensive pisciculture activities in reservoirs, it is essential to have information on the limnological characteristics of their contributing water bodies, its peculiarities and support capacity. Therefore, the study aimed to verify the feasibility of implementing intensive pisciculture adopting net cages in the reservoir of the Small Hydroelectric Plant (PCH) Boa Sorte, Tocantins, evaluating the favorable locations for installation of net cages, the limnological characteristics and the support capacity of the water bodies. The reservoir is located on the Palmeiras River, which belongs to Palma River basin and integrates the Paranã River basin, which is an important tributary of the Tocantins River. To identify areas favorable to the establishment of the aquaculture park, the entire reservoir area was analyzed, making up an area of 232 ha of water depth, where the majority, 141 ha, were considered favorable. After that, the limnological parameters were analyzed, namely: Temperature, $\mathrm{pH}$, dissolved oxygen, transparency, chlorophyll-a, total phosphorus, ammonia, nitrite and nitrate. Al parameters, except for total phosphorus, met the values recommended in CONAMA (2005) $\mathrm{n} 0357$ resolution. The average concentration of total phosphorus during the study period was $0.13 \mathrm{mg}$.L-1, which demonstrates that the support capacity of the reservoir has already been exceeded. In view of the data presented in this study, it was concluded that fish farming in net cages is not recommended in PCH Boa Sorte reservoir, as such activity can aggravate the eutrophication process existing in the water body under study.
\end{abstract}

Keywords: Supportability; Pisciculture; Reservoir; Fish cage.

Topic: Desenvolvimento, Sustentabilidade e Meio Ambiente

Reviewed anonymously in the process of blind peer.

Adriano Silva Figueredo (ID)

Instituto Federal do Tocantins, Brasil

http://lattes.cnpq.br/4508780340790599

http://orcid.org/0000-0002-5619-8437

adriano.figueredo@gmail.com

Ítalo Cordeiro Silva Lima

Instituto Federal do Tocantins, Brasil

http://lattes.cnpq.br/0251861575082615

http://orcid.org/0000-0001-6326-7974

italo.lima@ifto.edu.br

Deusiano Florêncio dos Reis

Universidade Federal do Tocantins, Brasil

http://lattes.cnpq.br/1018309854747533

http://orcid.org/0000-0003-1801-1640

deusiano@uft.edu.br

Luana Siqueria Fiuza (1)
Universidade Federal do Ceará
http://lattes.cnpq.br/8891398728820728
$\frac{\text { http://orcid.org/0000-0002-7060-7081 }}{\text { luafiuza@gmail.com }}$
Otacílio Silveira Junior (D)
Instituto Federal do Tocantins, Brasil
http://lattes.cnpq.br/5396347125642548
$\underline{\text { http://orcid.org/0000-0002-0784-5335 }}$
otacilio.junior@ifto.edu.br
Luiz Norberto Lacerda Magalhães Filho
Instituto Federal do Tocantins, Brasil
http://lattes.cnpq.br/2108889543462019
$\underline{\text { http://orcid.org/0000-0003-4109-8828 }}$
luiznorberto.filho@ifto.edu.br

Virgilio Lourenço da Silva Neto Instituto Federal do Tocantins, Brasil http://lattes.cnpq.br/0610186934356725 http://orcid.org/0000-0002-1004-0191 virgilio.neto@ifto.edu.br
Referencing this:

FIGUEREDO, A. S.; LIMA, I. C. S.; REIS, D. F.; FIUZA, L. S.; SILVEIRA JUNIOR, O.; MAGALHÃES FILHO, L. N. L.; SILVA NETO, V. L.. Viabilidade de implantação de tanques-rede no reservatório da $\mathrm{PCH}$ do estado do Tocantins, Brasil. Revista Ibero Americana de Ciências Ambientais, v.12, n.4, p.504-519, 2021. DOI: http://doi.org/10.6008/CBPC21796858.2021 .004 .0039 


\section{INTRODUÇÃO}

A piscicultura brasileira vem se consolidando no agronegócio, por meio de uma melhor organização em sua cadeia produtiva. Os reservatórios e lagos disponíveis despertam o interesse dos piscicultores pelo cultivo em tanques-rede, devido ao menor investimento necessário para implantação de estruturas produtivas em comparação aos viveiros escavados e à qualidade dos recursos hídricos disponíveis, com excelentes condições para o desenvolvimento da piscicultura (PEDROZA FILHO et al., 2014). A piscicultura configura-se como uma alternativa altamente rentável ao sistema econômico e produtivo, pois se configura como uma atividade concomitante ao uso para geração de energia, não causando prejuízos entre si, e gerando renda para as comunidades às margens do reservatório.

Atualmente, o Brasil conta com mais de 3,5 milhões de ha de lâmina d'água em reservatório de usinas hidrelétricas (ANEEL, 2002). O estado do Tocantins possui 159.800 ha de lâmina d'água em reservatórios de Usinas Hidrelétricas (UHE's) em operação; 12.196 ha de lâmina d'água em reservatórios de Pequenas Centrais Hidrelétricas (PCH's); e 51.716 ha em reservatórios de Projetos Hidroagrícolas (SEAGRO, 2017). Uma região que merece destaque é o sudeste do estado do Tocantins, que hoje possui diversos empreendimentos hidrelétricos, Pequenas Centrais Hidrelétricas $(\mathrm{PCH})$, que formaram reservatórios, e tem despertado interesse para a produção de peixes em tanques-rede. Dentre as PCH's implantadas, podemos destacar as localizadas no rio Palmeiras.

O rio Palmeiras, localizado no estado do Tocantins, com suas nascentes nas encostas da Serra Geral que divide os estados do Tocantins e Bahia, deságua no rio Palma e integra a bacia do rio Paranã, sendo este um importante tributário da margem direita do rio Tocantins (SEPLAN, 2012). Seus afluentes mais importantes localizam-se na margem esquerda, destacando-se o Ribeirão do Inferno ou Bonito, cujo encontro ocorre nas partes mais baixas de sua bacia. Pela margem direita, os afluentes são reduzidos a pequenos cursos d'água.

A produção de peixes em tanques-rede é a alternativa de investimento de menor custo e com rápida implantação, podendo permitir o uso adequado do recurso hídrico e o rápido desenvolvimento da piscicultura nacional (KUBITZA, 1999). O sistema de tanques-rede vem sendo desenvolvido no país por meio do uso de águas públicas federais e estaduais oriundas de usinas hidroelétricas. Esse sistema consiste basicamente em utilizar esses corpos d'água para instalação dos tanques feitos de estruturas de tela, onde os peixes são confinados e alimentados com ração (SCHULTER et al., 2017).

A piscicultura intensiva praticada em reservatórios, através da criação em tanques-rede, se não realizada de forma adequada, atendendo aos requisitos legais e ambientais, pode causar deterioração da qualidade da água, o que exige a devida atenção. Porém, a prática da atividade de produção de peixes pode ser realizada com sustentabilidade. Para que isso ocorra, é indispensável conhecer as características límnicas do corpo hídrico onde se pretende implantar projetos de piscicultura e dimensionar sua capacidade de suporte.

Além disso, é importante também ter conhecimento do nível máximo de produção que pode ser 
suportado pelo meio ambiente, os locais que atendem aos aspectos técnicos para a implantação de tanquesrede e os parâmetros físico-químicos de qualidade da água exigidos para a prática da piscicultura. Portanto, considerando a possibilidade de indicar locais que possam ser utilizados para implantação de parques aquícolas, o objetivo deste estudo foi avaliar a viabilidade da implantação de um projeto de piscicultura em tanques-rede no reservatório da PCH Boa Sorte no Estado do Tocantins, Brasil.

\section{MATERIAIS E MÉTODOS}

\section{Local experimental}

A área avaliada é um reservatório da PCH Boa Sorte, que é formado pelo barramento do rio Palmeiras, ocupa áreas pertencentes aos municípios de Dianópolis (margem direita) e Novo Jardim (margem esquerda) no Estado do Tocantins, Brasil (Figura 1). Sua bacia hidráulica possui 232 ha com capacidade acumulativa no nível máximo normal de $18.300 .000 \mathrm{~m}^{3} \mathrm{e}$ área de drenagem de $1.840 \mathrm{~km}^{2}$.

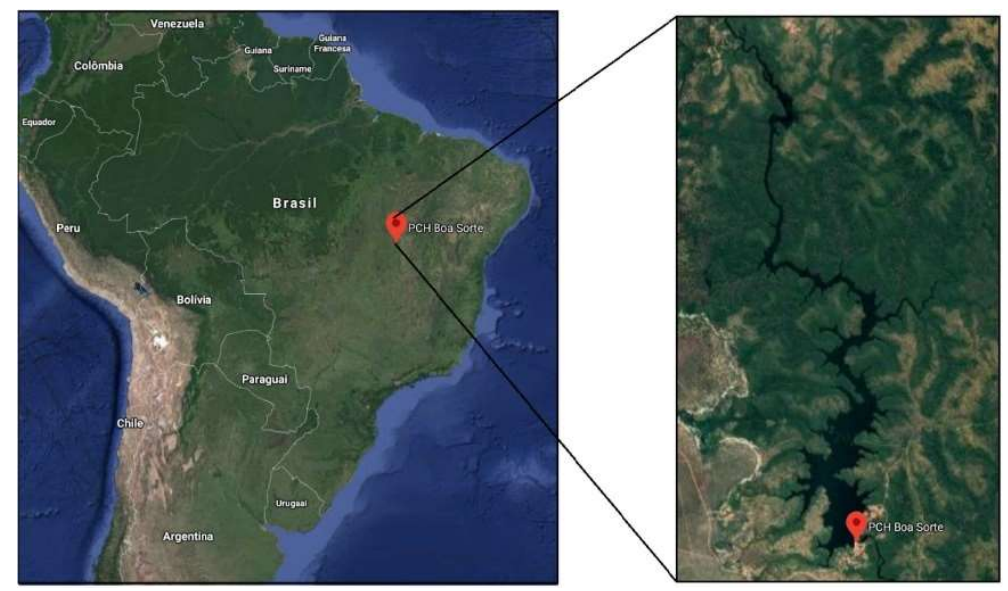

Figura 1: Localização do reservatório da PCH Boa Sorte. Fonte: imagem modificada do Google Maps.

O rio Palmeiras pertence à sub bacia do rio Palma e bacia Paranã, importante tributário da margem direita do rio Tocantins. Seus afluentes mais importantes localizam-se na margem esquerda, com destaque para o Ribeirão do Inferno ou Bonito, cujo encontro ocorre nas partes mais baixas de sua bacia. Na margem direita, os afluentes são reduzidos a pequenos cursos d'água.

Segundo Souza et al. (2019), a classificação climática de Thornthwaite aplicada ao longo da Bacia do rio Palma é C2A'wa' (clima subúmido úmido, megatérmico, com moderada deficiência de água no inverno, e regime de eficiência de temperatura normal para o tipo climático megatérmico).

\section{Pré-seleção de áreas aquícolas}

A metodologia adotada para a pré-seleção de áreas com potencial aquícola no reservatório da PCH Boa Sorte foi a coleta de dados de fatores restritivos e qualitativos para toda a represa proposto por Webber et al. (2015).

Inicialmente, as informações foram coletadas por meio de análise de imagens de satélite, foram observados os usos do solo do entorno do reservatório; a presença de acessos; e larguras de diferentes locais 
do reservatório. Uma vez identificados esses fatores, foram coletados dados in loco, tais como: profundidade e dimensão dos locais propícios para o estabelecimento de parques aquícolas; presença de paliteiros; fontes de poluição; balneários de lazer; processos erosivos; captação de água; presença de plantas macrófitas e degradação da Área de Preservação Permanente do reservatório. Utilizando o navegador GPS (Garmin Etrex Legend), foram plotados todos os pontos do reservatório que apresentaram esses fatores.

Para levantamento da profundidade da coleta de dados em áreas com potencial para instalação de tanques-rede, foi escolhido o mês de abril de 2018, início da estação seca, as medições foram realizadas com um peso de $10 \mathrm{~kg}$ fixado a uma corda. As profundidades dessas áreas foram coletadas a uma distância de quinze metros de cada margem e no centro do corpo hídrico (Figura 2).

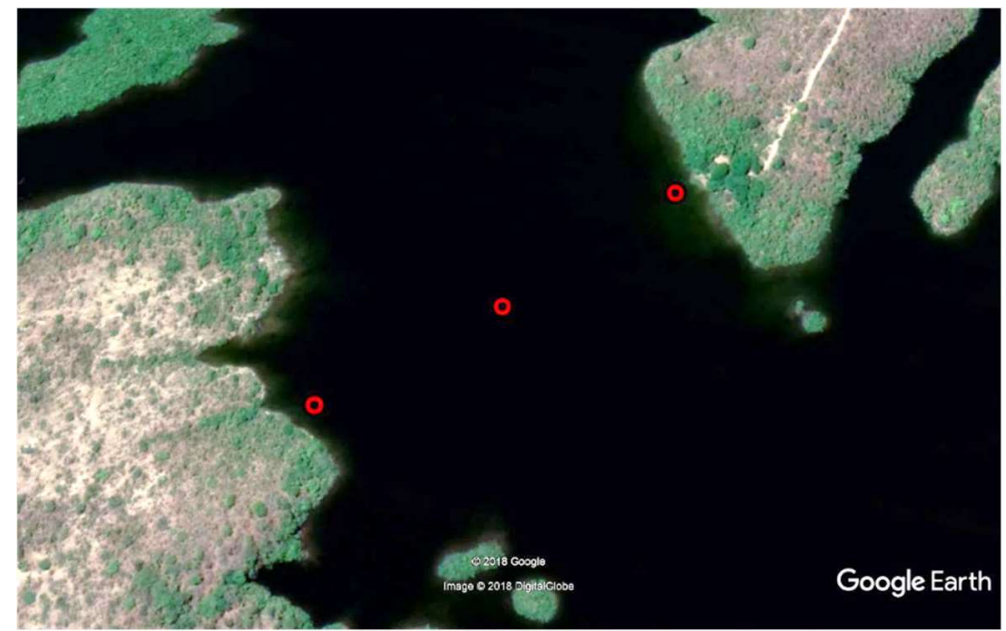

Figura 2: Exemplo de locais de levantamento de profundidade em áreas com potencial para instalação de tanquesrede no reservatório da PCH Boa Sorte, Brasil. Fonte: imagem modificada do Google Earth.

\section{Amostragem e análises limnológicas}

A região do Brasil Central tem uma variação sazonal bem definida com uma estação chuvosa no verão (outubro-março) e uma estação seca no inverno (abril-setembro) (NIMER, 1979). Para avaliação espacial e temporal das variáveis da água do reservatório da PCH Boa Sorte, foram realizadas amostragens semestrais, uma no período de seca e outra no período das chuvas, entre os anos de 2013 e 2017. As amostras de água foram coletadas da superfície ( $50 \mathrm{~cm}$ ) em três pontos no reservatório, o primeiro ponto amostral (P1) sendo localizado no início do reservatório na interface lótica; o segundo ponto amostral (P2) localizado na região central do reservatório; e o terceiro ponto amostral (P3) localizado próximo ao barramento (Tabela 1; Figura 3).

Tabela 1: Descrição dos pontos de coleta no reservatório da PCH Boa Sorte.

\begin{tabular}{llc}
\hline Pontos & Descrição & Coordenadas Geográficas \\
\hline P1 & Início do reservatório & $11^{\circ} 49^{\prime} 8.23^{\prime \prime S} 46^{\circ} 47^{\prime} 18.76^{\prime \prime} \mathrm{O}$ \\
P2 & Região central do reservatório & $11^{\circ} 51^{\prime} 37.08^{\prime \prime} S 46^{\circ} 46^{\prime} 5.87^{\prime \prime O}$ \\
P3 & Próximo ao eixo do barramento & $11^{\circ} 53^{\prime} 16.31^{\prime \prime} S 46^{\circ} 46^{\prime} 16.11^{\prime \prime O}$ \\
\hline
\end{tabular}

Os parâmetros físico-químicos avaliados foram: Temperatura $\left({ }^{\circ} \mathrm{C}\right)$; Potencial Hidrogeniônico $(\mathrm{pH})$; Oxigênio Dissolvido (mg/L); Transparência da água (M), através da utilização do disco de Secchi; Clorofila "a" ( $\mu \mathrm{g} / \mathrm{L})$; Fósforo Total (mg/L); Amônia (mg/L); Nitrito (mg/L); e Nitrato (mg/L). Os parâmetros foram analisados 
de acordo com a metodologia proposta nos Standard Methods for the Examination of Water and Wasterwater - APHA (2005).

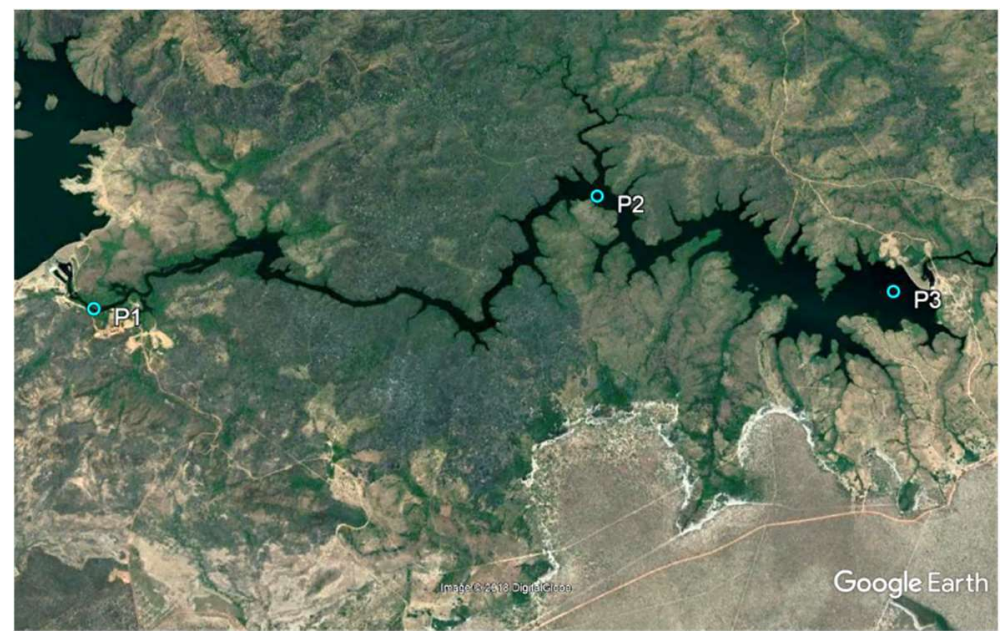

Figura 3: Pontos de coleta de água no reservatório da PCH Boa Sorte.

A estimativa da capacidade de suporte do reservatório da PCH Boa Sorte para fins de piscicultura intensiva foi realizada utilizando o método desenvolvido por Dillon et al. (1974). O modelo considerou a concentração média anual de fósforo total $(\mu \mathrm{g} / \mathrm{L})$ durante o período de estudo. O limite de lançamento de fósforo total no meio ambiente é de $0,05 \mathrm{mg} \cdot \mathrm{L}^{-1}$ para águas Classe II, conforme Resolução 357/05.

O coeficiente de sedimentação do fósforo $(R)$ foi determinado de acordo com a equação (Eq. 1):

$$
R=1 /\left(1+0,614 \cdot \rho^{0,491}\right) \quad \text { Eq. } 1
$$

Em que: $\rho=$ taxa de renovação da água do ambiente em número de vezes por ano, calculada como descrito por Santos

Para o cálculo da capacidade de suporte (L), foi utilizada a expressão (Eq 2.): et al. (2001).

$$
L=\Delta P \cdot(Z \cdot \rho) /(1-R)
$$

Onde: $\Delta \mathrm{P}$ = limite máximo para lançamento de fósforo total para o ambiente obtido da fórmula (Eq. 3):

$$
\triangle \mathrm{P}=\mathrm{PF}-\mathrm{PI} \quad \text { Eq. } 3
$$

Onde: $\mathrm{PI}=$ concentração média de fósforo total mensurado durante o período de estudo $\left(\mathrm{mg} \cdot \mathrm{L}^{-1}\right) ; \mathrm{PF}=$ concentração limite de fósforo estabelecida pelo órgão competente $\left(\mathrm{mg} \cdot \mathrm{L}^{-1}\right) ; Z=$ profundidade média do local $(\mathrm{m})$.

Em seguida, foi calculada a carga de fósforo autorizável em todo o Reservatório (Lr), que será em $\mathrm{mg} / a n o$, utilizando o L, que representa a máxima carga de fósforo autorizável por metro quadrado, multiplicando o valor obtido pela área de superfície do reservatório em $\mathrm{m}^{2}$ (Eq 4.):

$$
\mathrm{Lr}=\mathrm{L} . \mathrm{A}
$$

Eq. 4

Após o cálculo da capacidade de suporte do reservatório da PCH Boa Sorte, foi possível estimar a quantidade máxima de peixes que pode ser produzida. Para realizar essa estimativa, a tilápia do Nilo (Oreochromis niloticus) foi usada como referência. A escolha se justificou por ser o peixe mais produzido no Brasil. A proporção de fósforo retida na carcaça da tilápia corresponde a $0,9 \%$ de seu peso úmido (DANTAS et al., 2007). Ou seja, para cada 1 tonelada de peixe produzida, 9 quilogramas de fósforo ficam retidos na carcaça do peixe. Neste trabalho, foram utilizadas concentração de fósforo na ração (1\%) e taxa de conversão alimentar $(1,5: 1,0)$ que seriam encontradas em condições ideais de produção.

Utilizando o modelo proposto por Beveridge (1984) em consórcio ao modelo Dillon et al. (1974), a 
carga de fósforo aportada no reservatório é estimada após produção de uma tonelada de peixe (Eq 5.):

$$
\mathrm{Pe}=(\operatorname{Pr} . \mathrm{TCA})-\mathrm{Pd} \quad \text { Eq. } 5
$$

Onde: $\mathrm{Pe}=$ Carga de fósforo gerada para produzir uma tonelada de peixe $(\mathrm{kg} / \mathrm{t}$ de peixe); $\mathrm{Pr}=$ Concentração de fósforo na ração ( $\mathrm{kg} / \mathrm{t}$ de ração); $\mathrm{Pd}$ = Concentração de fósforo no peixe despescado ( $\mathrm{kg} / \mathrm{t}$ de peixe despescado); $\mathrm{e}$ TCA = Taxa de conversão alimentar.

Por fim, para calcular a produção anual de peixes suportada pelo reservatório, respeitando o incremento de fósforo, utiliza-se a seguinte equação (Eq. 6.):

$$
\mathrm{Cs}=\mathrm{L} . \mathrm{A} / \mathrm{Pe} \quad \text { Eq. } 6
$$

Onde: $\mathrm{Cs}$ = Produção anual de peixe suportada pelo reservatório (toneladas/ano); L = Carga de fósforo $\left(\mathrm{kg} / \mathrm{m}^{2} / \mathrm{ano}\right) ; \mathrm{A}=$ Área do reservatório $\left(\mathrm{m}^{2}\right) ;$ e $\mathrm{Pe}=$ Carga de fósforo gerada para produzir uma tonelada de peixe $(\mathrm{kg} / \mathrm{t}$ de peixe).

Os dados do reservatório da PCH Boa Sorte necessários para o cálculo da capacidade de suporte são apresentados na Tabela 2 (VLB, 2006).

Tabela 2: Volume de água (V), área da bacia hidráulica (A) e profundidade média (Z) na cota média, vazão média anual liberada (Q), descarga média anual $(\rho)$ e tempo médio de residência da água $(1 / \rho)$ do reservatório da PCH Boa Sorte.

\begin{tabular}{llllll}
\hline Reservatório & $\mathrm{V}\left(10^{6} \mathrm{~m}^{3}\right)$ & $\mathrm{A}\left(10^{6} \mathrm{~m}^{2}\right)$ & $\mathrm{V} / \mathrm{A}=\mathrm{Z}(\mathrm{m})$ & $\begin{array}{l}\mathrm{Q} \\
\left(10^{6} \mathrm{~m}^{3} \mathrm{ano}^{-1}\right)\end{array}$ & $\begin{array}{l}\rho=\mathrm{Q} / \mathrm{V} \\
(\mathrm{ano}-1)\end{array}$ \\
\hline $\mathrm{PCH}$ Boa Sorte & 18,3 & 2,32 & 7,89 & 1,26 & 0,069 \\
\hline
\end{tabular}

\section{Análise estatística}

Os dados obtidos foram submetidos à análise de variância (ANOVA) e quando observadas diferenças significativas $(P<0,05)$ foi aplicado o teste de Tukey a $5 \%$ de significância, utilizando-se o software Statistical Analysis System $\left(\mathrm{SAS}^{\circledR}\right)$. As análises de componentes principais foram realizadas usando a matriz de correlação. Isso permite padronizar a variabilidade dos dados retirando o efeito das diferenças de magnitude entre as variáveis utilizadas. O critério de seleção do eixo utilizado foi Kaiser-Guttman (GUTTMAN, 1954; KAISER, 1958). As variáveis limnológicas consideradas para a PCA foram: nitrogênio inorgânico (amônia, nitrito e nitrato), fósforo total, $\mathrm{pH}$, oxigênio dissolvido, temperatura da água, transparência e clorofila.

\section{RESULTADOS E DISCUSSÃO}

Na Figura 4 mostra os locais favoráveis e não favoráveis para o cultivo de peixes nos tanques-rede avaliados na área de estudo. A área do reservatório da PCH Boa Sorte totalizou 232 hectares (ha) de lâmina d'água. Dentre as áreas avaliadas, 141 ha foram considerados viáveis para implantação de tanques-rede no reservatório da PCH Boa Sorte (Figura 4).

A profundidade média verificada nos pontos amostrados dentro da área favorável (141 ha) para implantação dos tanques-rede no reservatório da PCH Boa Sorte foi de 10 metros nas margens (distância de 15 metros da borda do reservatório) e 17 metros no centro do corpo hídrico. Como a represa não sofre depleções consideráveis conforme as recomendações propostas pela ANA (2018) e as profundidades médias foram acima de 10 metros, essas medições foram realizadas apenas no período de chuvas. 


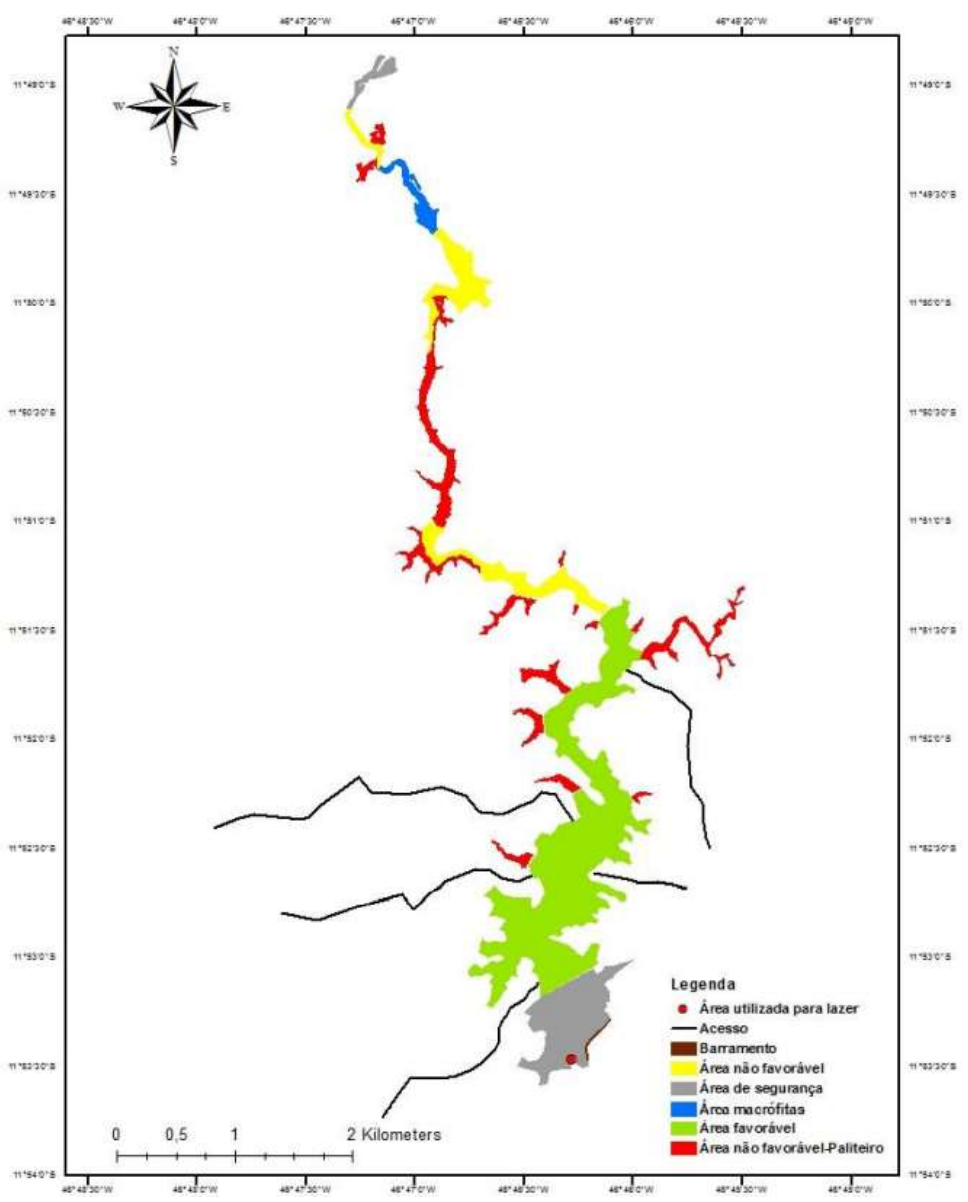

Figura 4: Mapa de classificação das áreas favoráveis e não favoráveis para o cultivo de peixes em tanques-rede no reservatório da $\mathrm{PCH}$ Boa Sorte.

As áreas identificadas atendem a Instrução Normativa Interministerial (INI) n 07/2005 (BRASIL, 2005) que indica que a profundidade da área onde será implantado o parque aquícola é uma vez a altura dos tanques-rede utilizados entre a parte inferior do tanque e o fundo do reservatório. Como os tanques-rede geralmente utilizados em parques aquícolas são de $3 \mathrm{~m} \times 3 \mathrm{~m} \times 2 \mathrm{~m}$, a profundidade da "área apta" do reservatório da $\mathrm{PCH}$ Boa Sorte atende a esse critério, facilitando a diluição dos resíduos e contribuindo para a qualidade da água.

Os locais com a presença de paliteiros foram indicados como não favoráveis à instalação dos tanquesrede, por serem considerados entraves para a instalação dos tanques, podendo causar danos a sua estrutura, por atrito, ocasionando a fuga de peixes.

No reservatório da PCH Boa Sorte, quatro táxons de macrófitas aquáticas foram observados: o primeiro da família Poaceae do gênero Brachiaria da espécie Subquadripara; o segundo da família Cyperaceae do gênero Elioscharis da espécie calva; o terceiro da família Poaceae do gênero Luziola da espécie Fragilis; e o quarto da família Typhaceae do gênero Typha da espécie Domingesis. Espacialmente estão distribuídas em áreas próximas ao início do reservatório, áreas que não apresentam características para implantação dos tanques-rede (Figura 4). Tendo em vista que macrófitas aquáticas podem ser indicadoras de processo de eutrofização da água, que é causado pelo excesso de nutrientes, sendo os principais, fósforo e o nitrogênio, as áreas com presença desses organismos foram consideradas como não favoráveis à implantação dos tanques-rede (WEBBER et al., 2015). 
A vegetação da Área de Preservação Permanente (APP) do reservatório da PCH Boa Sorte não apresentou perturbações apontando para um bom estádio de conservação, o que contribui para uma boa qualidade da água. Não foram encontrados processos erosivos nas margens do reservatório durante os levantamentos realizados para obtenção dos dados para este estudo. Áreas com processos erosivos próximos ao corpo hídrico podem aportar sedimentos que interferem na qualidade da água, podendo provocar assoreamento e dificultar o acesso ao parque aquícola.

As margens do reservatório não possuem indústrias e atividades potencialmente poluidoras. As fontes poluidoras no entorno dos reservatórios podem aumentar o aporte de nutrientes e contribuir para a eutrofização dos corpos hídricos, além de exercer um potencial perigo de contaminação de peixes (VIEIRA, 2009).

No entorno do reservatório, há produção de peixes em viveiros escavados. A captação de água para abastecimento desses viveiros é realizada no reservatório da PCH Porto Franco, empreendimento localizado a montante da PCH Boa Sorte. No reservatório da PCH Boa Sorte, não foram identificados pontos de captação de água. Reservatórios com captação de água, principalmente quando destinado ao consumo humano, podem gerar conflitos com as atividades desenvolvidas, como a piscicultura em tanques-rede (SUBASINGHE et al., 2009).

Quanto às áreas utilizadas para lazer, apenas um ponto foi identificado. Este ponto fica próximo ao barramento, localizado nos limites da área de segurança da PCH Boa Sorte (Figura 4). O reservatório da PCH Boa Sorte, por se encontrar distante da área urbana do município de Dianópolis (35 km), e por ser de difícil acesso, é pouco utilizado para atividades de lazer. As áreas onde existem balneários de lazer são consideradas como não favorável à implantação dos tanques-rede, por estarem em conflito com o uso.

\section{Caracterização limnológica da água do reservatório da PCH boa sorte}

Os valores dos parâmetros de qualidade de águas analisados durante o período de estudo são apresentados na Tabela 3.

Tabela 3: Valores dos parâmetros de qualidade da água nos diferentes anos, estações e pontos amostrais no reservatório da PCH Boa Sorte.

\begin{tabular}{|c|c|c|c|c|c|c|c|c|c|c|c|}
\hline Ano & Estação & $\begin{array}{l}\text { Pontos } \\
\text { Amostrais }\end{array}$ & Temp. $\left({ }^{\circ} \mathrm{C}\right)$ & $\begin{array}{l}\text { pH } \\
\text { (E.L.) }\end{array}$ & $\begin{array}{l}\text { O.D. } \\
\left.\text { (mg. } \mathrm{L}^{-1}\right)\end{array}$ & Transp.(m) & $\begin{array}{l}\text { Cl-a } \\
\left(\mu g . L^{-1}\right)\end{array}$ & $\begin{array}{l}\text { Fósforo } \\
\left(\mathrm{mg} . \mathrm{L}^{-1}\right)\end{array}$ & $\begin{array}{l}\text { Amônia } \\
\text { (mg. } \mathrm{L}^{-1} \text { ) }\end{array}$ & $\begin{array}{l}\text { Nitrito } \\
\left(\mathrm{mg} \cdot \mathrm{L}^{-1}\right)\end{array}$ & $\begin{array}{l}\text { Nitrato } \\
\left(\mathrm{mg}^{-\mathrm{L}^{-1}}\right)\end{array}$ \\
\hline 2013 & seca & P1 & 26.42 & 6.91 & 8.7 & 3.1 & 1.18 & 0.02 & 0.14 & 0 & 0.1 \\
\hline 2013 & seca & $\mathrm{P} 2$ & 28.42 & 7.21 & 8.18 & 3.28 & 2.17 & 0.09 & 0.02 & 0.001 & 0.1 \\
\hline 2013 & seca & P3 & 26.96 & 7.27 & 8.55 & 3.65 & 6.5 & 0.03 & 0.17 & 0.001 & 0 \\
\hline 2013 & chuva & $\mathrm{P} 1$ & 28.06 & 6.41 & 7.22 & 2.4 & 11.63 & 0.02 & 0.05 & 0.002 & 0.4 \\
\hline 2013 & chuva & $\mathrm{P} 2$ & 30.1 & 6.65 & 6.51 & 1.9 & 2.96 & 0.23 & 0.07 & 0.006 & 0.2 \\
\hline 2013 & chuva & P3 & 29.99 & 6.9 & 6.36 & 2.1 & 2.76 & 0.01 & 0.05 & 0.003 & 0.2 \\
\hline 2014 & seca & $\mathrm{P} 1$ & 27.17 & 6.2 & 5.7 & 3.2 & 8.47 & 0.38 & 0.08 & 0.005 & 1.3 \\
\hline 2014 & seca & $\mathrm{P} 2$ & 28.56 & 6.2 & 5.74 & 3.4 & 0.2 & 0.45 & 0.11 & 0.002 & 0.2 \\
\hline 2014 & seca & P3 & 28.63 & 6.1 & 5.67 & 3.4 & 3.35 & 0.44 & 0.08 & 0 & 2.1 \\
\hline 2014 & chuva & P1 & 27.84 & 6.7 & 5.82 & 3.4 & 7.29 & 0.24 & 0.06 & 0 & 0.4 \\
\hline 2014 & chuva & P2 & 29.76 & 7.2 & 5.5 & 2.35 & 10.44 & 0.22 & 0.03 & 0 & 0 \\
\hline 2014 & chuva & P3 & 29.87 & 6.7 & 5.37 & 2.25 & 3.74 & 0.18 & 0.03 & 0 & 0 \\
\hline 2015 & seca & P1 & 26.73 & 8 & 7 & 2.8 & 3.35 & 0.09 & 0.02 & 0.002 & 0 \\
\hline 2015 & seca & $\mathrm{P} 2$ & 26.74 & 7.8 & 7.01 & 3.8 & 0.59 & 0.03 & 0.04 & 0 & 0 \\
\hline 2015 & seca & P3 & 27.93 & 8 & 6.94 & 3.75 & 0.59 & 0.26 & 0.09 & 0 & 0 \\
\hline
\end{tabular}




\begin{tabular}{llllllllllll}
\hline 2015 & chuva & P1 & 26.73 & 7.31 & 7 & 2.1 & 0.39 & 0.09 & 0.02 & 0.002 & 0 \\
\hline 2015 & chuva & P2 & 29.81 & 7.5 & 5.78 & 1.95 & 2.56 & 0 & 0 & 0.008 & 0 \\
\hline 2015 & chuva & P3 & 29.69 & 7.8 & 6.13 & 1.75 & 2.56 & 0 & 0 & 0 \\
\hline 2016 & seca & P1 & 25.76 & 6.02 & 7.35 & 3 & 3.15 & 0.16 & 0.07 & 0.002 & 0 \\
\hline 2016 & seca & P2 & 25.93 & 6.27 & 7.42 & 3.2 & 2.56 & 0.12 & 0.04 & 0.003 & 0 \\
\hline 2016 & seca & P3 & 26.3 & 6.06 & 7.66 & 3.4 & 2.76 & 0.07 & 0.03 & 0.003 & 0 \\
\hline 2016 & chuva & P1 & 25.21 & 6.32 & 7.12 & 2.5 & 4.12 & 0.09 & 0.06 & 0.003 & 0 \\
\hline 2016 & chuva & P2 & 25.34 & 6.47 & 7.28 & 2.6 & 3.44 & 0.1 & 0.05 & 0.003 & 0 \\
\hline 2016 & chuva & P3 & 25.3 & 6.26 & 6.98 & 2.5 & 3.21 & 0.06 & 0.07 & 0.004 & 0.5 \\
\hline 2017 & seca & P1 & 24.91 & 7.12 & 7.44 & 2.25 & 1.18 & 0.06 & 0.01 & 0.002 & 0 \\
\hline 2017 & seca & P2 & 24.89 & 6.98 & 7.32 & 2.9 & 0.59 & 0.08 & 0.01 & 0.002 & 0 \\
\hline 2017 & seca & P3 & 24.71 & 6.91 & 7.41 & 3.85 & 0.99 & 0.03 & 0.02 & 0.002 & 0 \\
\hline 2017 & chuva & P1 & 31.7 & 6.72 & 7.54 & 3.1 & 1.77 & 0.16 & 0.04 & 0 \\
\hline 2017 & chuva & P2 & 32.5 & 6.98 & 7.13 & 3.1 & 1.97 & 0.14 & 0.03 & 0 \\
\hline 2017 & chuva & P3 & 31.4 & 7.08 & 7.51 & 3.2 & 1.58 & 0.15 & 0.02 & 0 \\
\hline
\end{tabular}

Ocorreram variações muito significativas $(\mathrm{P}<0,0001)$ na temperatura entre os períodos de coleta (seca e chuva), sendo as maiores temperaturas da água encontradas no período chuvoso; e diferenças significativas entre os pontos amostrais (P1, P2 e P3), onde P1 diferiu dos demais pontos. Não houve diferenças significativas entre os períodos de coleta e os pontos amostrais $(P>0,05)$. Na área do reservatório da PCH Boa Sorte, a temperatura da água variou de $24,71^{\circ} \mathrm{C}$ (P3 julho/2017) a $32,5^{\circ} \mathrm{C}$ (P2 novembro/2017) (Figura 5).

A sazonalidade no estado do Tocantins está bem definida e passa a ser um fator determinante nos processos dos ecossistemas aquáticos. Landa (1999), descreve o resfriamento da água no outono (período seco) e aquecimento no verão (período de chuva), onde a alta umidade relativa do ar pode limitar a perda de calor da água, fato que esclarece a diferença de temperatura entre os períodos de coleta (seca e chuva). Damasceno (2008), por outro lado, atribui os maiores valores de temperatura da água no período chuvoso à contribuição pluviométrica e à baixa variação da temperatura média do ar ao longo do dia. A temperatura média no reservatório da $\mathrm{PCH}$ Boa Sorte durante o outono foi de $26,67^{\circ} \mathrm{C}$ e no verão $28.88^{\circ} \mathrm{C}$.

Os peixes são animais pecilotérmicos, a dinâmica de crescimento muscular não é determinada apenas pela genética, mas também pelas condições ambientais, onde a temperatura da água influência diretamente no crescimento desses animais (WEATHERLEY et al., 1987). Quanto maior a temperatura (dentro da faixa de conforto térmico de uma espécie de peixe), maior será o consumo de alimento e a atividade metabólica, proporcionando um rápido crescimento para os peixes (CARNEIRO et al., 1999). A faixa ideal para crescimento varia de acordo com a espécie.

No reservatório da $\mathrm{PCH}$ Boa Sorte, houve diferenças significativas $(P<0,05)$ entre os períodos de coleta (seca e chuva), sendo que a maior transparência foi observada no período de seca; e entre períodos e pontos amostrais; e não houve diferença significativa entre os pontos amostrais $(P>0,05)$. Demonstrando que o período chuvoso influencia na transparência da água, devido ao carreamento de materiais particulados até o reservatório o que ocasiona um aumento de material em suspensão na água (SOUZA et al., 1996).

As águas, do reservatório da PCH Boa Sorte, apresentam boa transparência com variação de 1,75 m (P3 dezembro/2015) a 3,85 m (P3 junho/2017) (Figura 6), o que aponta para um ambiente com boa penetração de luz solar na coluna d'água, contribuindo para a fotossíntese de plantas aquáticas submersas e algas, aumentando a produção de alimentos (MÃMAR et al., 1986). Reservatórios com transparência da 
água acima de 2 metros fornecem pouco enriquecimento em nutrientes (SCHMITTOU, 1993), e a piscicultura pode ser desenvolvida em tanques-rede. O ponto amostral P3 apresentou o maior valor médio de transparência da água durante o estudo.

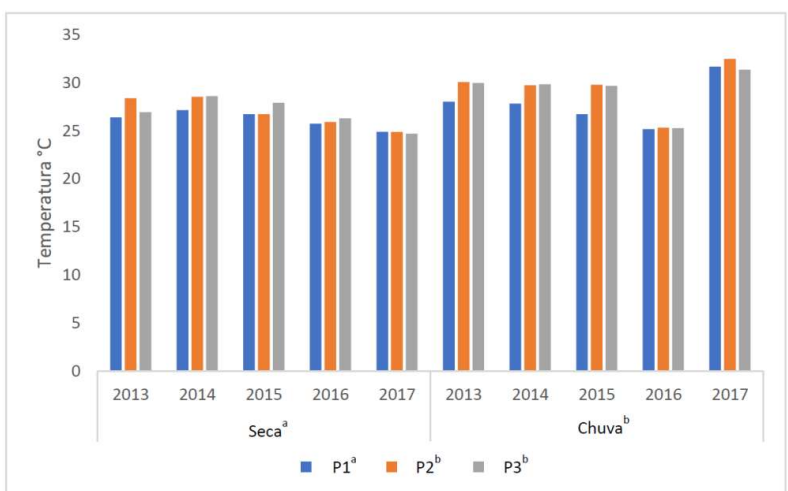

Figura 5: Variação da temperatura dos pontos amostrais durante os anos de 2013 a 2017, no reservatório da PCH Boa Sorte.

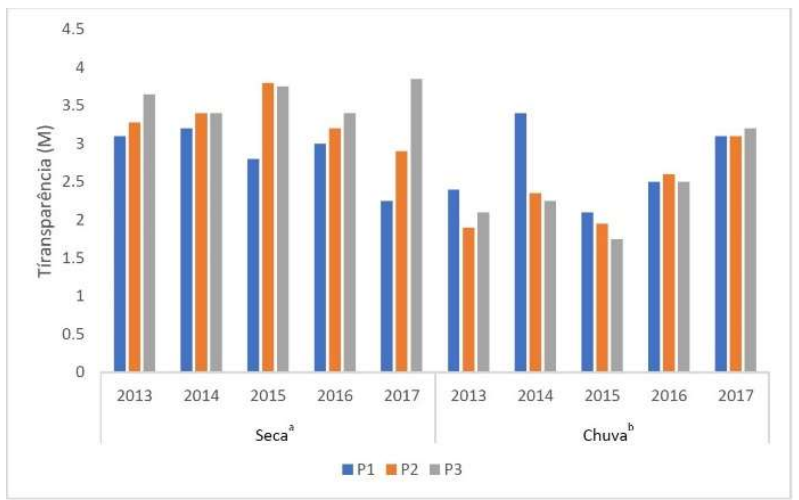

Figura 6: Variações na transparência da água dos pontos amostrais nos de 2013 a 2017, no reservatório da PCH Boa Sorte.

Os valores de $\mathrm{pH}$, ao longo do período (seca e chuva), não diferiram significativamente $(\mathrm{P}>0,05)$. Os valores obtidos, no reservatório da PCH Boa Sorte, durante o estudo variaram de 6,06 (P3 maio/2016) a 8,00 (P1 e P3 maio/2015), permanecendo dentro dos limites aceitáveis pela Resolução CONAMA 357/2005 para águas de Classe 2 (Figura 7).

A maioria das espécies de peixes se desenvolve melhor em uma faixa de pH entre 6,5 e 9,0 (BOYD, 1982). Águas com valores de pH constantes oferecem melhores condições para o desenvolvimento dos peixes do que águas com variações consideráveis de pH, com os melhores valores entre 7 e 8 (BOYD, 1982).

Entre os fatores limitantes para a piscicultura, podemos citar as baixas concentrações de oxigênio dissolvido na água. A fotossíntese e a atmosfera são as principais fontes naturais de oxigênio na água, e sua depleção está relacionada à respiração dos organismos aquáticos, perdas para atmosfera e decomposição de matéria orgânica (ESTEVES, 2011).

Diferenças muito significativas $(P<0,0001)$ de oxigênio dissolvido foram verificadas entre os períodos de amostragem (seca e chuva), sendo os maiores valores de oxigênio dissolvido encontrados no período de seca. Entre os pontos amostrais do reservatório houve diferença significativa $(P<0,05)$ nas concentrações de oxigênio dissolvido, P1 apresentou os maiores valores de oxigênio, seguido de P2 e P3, respectivamente, o que pode estar relacionado às características do ambiente amostrado, sendo P1 lótico, P2 interface lótico/lênticos e P3 lêntico.

As concentrações de oxigênio dissolvido obtidas nos pontos amostrais apresentaram bons valores de oxigenação, variando de 5,37 mg.L-1 (P3 dezembro/2017) a 8,70 mg.L-1 (P1 maio/2013) (Figura 18). Essas concentrações se enquadram dentro do estabelecido na Resolução CONAMA №. 357/2005 (não inferior a 5,0 mg. $\left.\mathrm{L}^{-1}\right)$ para águas de Classe 2 e indicam a capacidade do ambiente em manter a vida aquática, bem como o qualificam como bem oxigenado. 


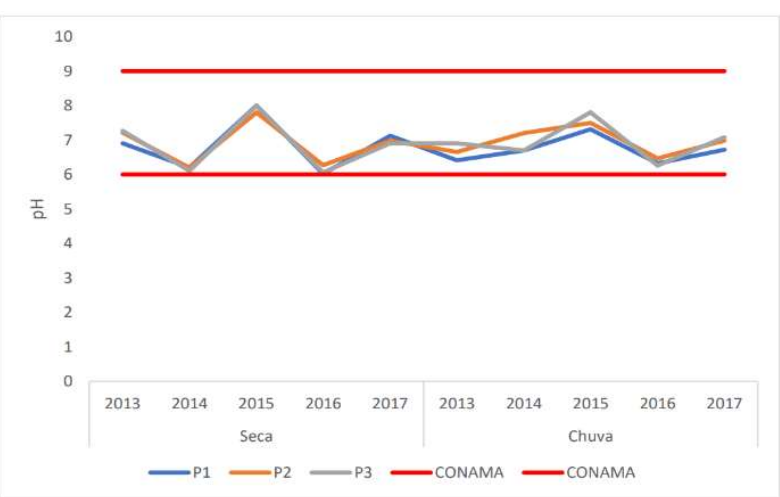

Figura 7: Variações do $\mathrm{pH}$ da água dos pontos amostrais durante os anos de 2013 a 2017, no reservatório da PCH Boa Sorte.

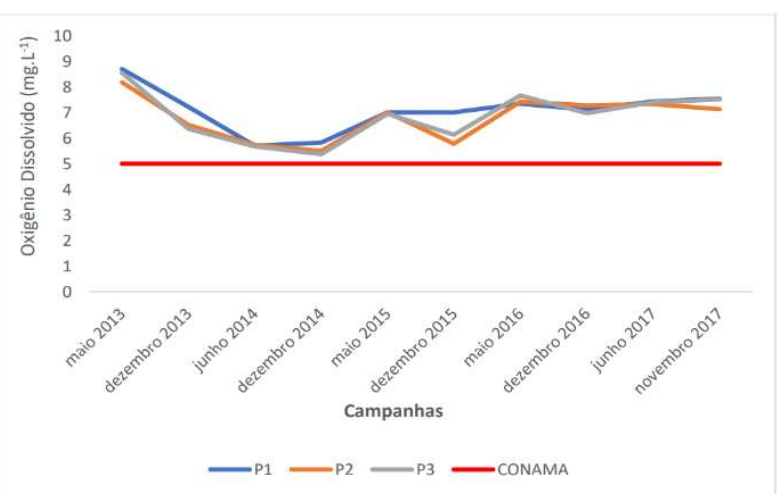

Figura 8: Variações do oxigênio dissolvido da água dos pontos amostrais nas campanhas dos períodos de seca e chuva durante os anos de 2013 a 2017, no reservatório da PCH Boa Sorte.

A concentração de clorofila-a é a principal variável que indica o processo de eutrofização e pode ser utilizada como uma representação indireta das concentrações de algas. No presente estudo, não houve diferenças significativas $(P>0,05)$ entre as concentrações de clorofila-a, durante o período de coleta (seca e chuva) e entre os pontos amostrais.

As concentrações de clorofila-a registradas no reservatório da $\mathrm{PCH}$ Boa Sorte durante o estudo variaram de 0,2 $\mu \mathrm{g} . \mathrm{L}^{-1}$ (P2 em junho de 2014) a 11,63 $\mu \mathrm{g} . \mathrm{L}^{-1}$ (P1 em dezembro de 2013), sendo inferiores a30 ]g. L-1 ${ }^{-1}$, como recomendação da Resolução CONAMA №. 357/2005 (Figura 9).

O fósforo é, em geral, o principal elemento que pode limitar a produção primária dos ecossistemas aquáticos. $\mathrm{O}$ aumento da disponibilidade e uso desse nutriente leva a aumento do estado trófico. $\mathrm{O}$ fósforo é considerado o macro mineral essencial para o crescimento e a reprodução dos peixes (ROY et al., 2003).

Não houve diferenças significativas $(P>0,05)$ entre as concentrações de fósforo total, no período de coleta (seca e chuva) e entre os pontos amostrais. Com exceção das amostras coletadas nos seguintes pontos e períodos, P1 e P3 (maio e dezembro de 2013); P2 (maio de 2015); e P3 (junho de 2017), os demais pontos amostrais levantados durante o estudo apresentaram valores acima do determinado pela Resolução 357/2005 do CONAMA para o elemento fósforo, sem adição aparente de poluição orgânica (Figura 10). Podemos supor que esses elevados valores podem estar relacionados à decomposição da matéria orgânica advinda da vegetação submersa presente no reservatório, que não foi totalmente removida durante o desmatamento da área, podendo contribuir para o aumento dos níveis de fósforo nas águas. Quevedo et al. (2011), relataram que as fontes naturais estão relacionadas com as cargas difusas de fósforo nos corpos hídricos, como a decomposição dos organismos aquáticos e vegetais em matas ciliares.

Reservatórios considerados oligotróficos apresentam concentração de fósforo total abaixo de 0,05 $\mathrm{mg} \cdot \mathrm{L}^{-1}$, enquanto os oligomesotróficos são aqueles com concentrações entre 0,05 e 0,1 mg. $\mathrm{L}^{-1}$. Diante das concentrações encontradas no reservatório da PCH Boa Sorte, podemos classificá-las como oligotrófico e oligomesotrófico, respectivamente, com tendência a eutrófico (ESTEVES, 1998).

Neste contexto, nos últimos anos têm se intensificado a busca de tecnologias para remediação de ambientes eutrofizados e reaproveitamento do fósforo para fins de fertilização agrícola, incluindo precipitação química de fósforo com sais metálicos, com eficiência de remoção de fósforo variando de $60 \%$ 
a 99\% de P recuperado (FROSSARD et al., 1997; BAKER et al., 1998; MORIYAMA et al., 2001) e remoção biológica, por meio do uso de bactérias (NEGADOMI et al., 2000), microalgas (VOLTOLINA et al., 1999) e zonas húmidas construídas (KÖRNER et al., 1998), com eficiência de remoção de fósforo variando de 50 \% a 99\% de P recuperado. Recentemente, Pantano et al. (2019) demonstraram que por meio do uso de biossorvente, a serragem, representa uma alternativa viável para depleção de fósforo em ambientes aquáticos. Além disso, Pantano et al. (2021) demonstraram que ao aplicar serragem para biossorção de fósforo no cultivo de alface e cebola, não foram observadas genotoxicidade, citotoxicidade e mutagenicidade, sendo, portanto, considerada uma tecnologia muito promissora para as condições apresentadas no presente estudo, de valores acima do determinado pela Resolução 357/2005 do CONAMA.

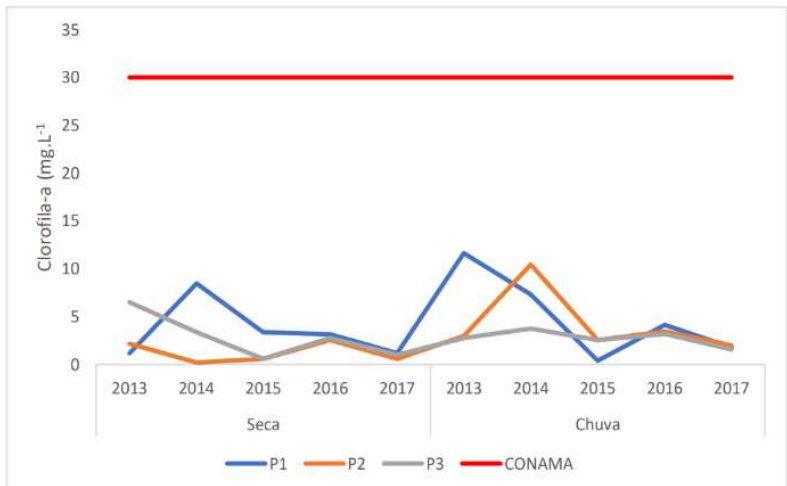

Figura 9: Variações da clorofila-a dos pontos amostrais nas campanhas dos períodos de seca e chuva durante os anos de 2013 a 2017, no reservatório da PCH Boa Sorte.

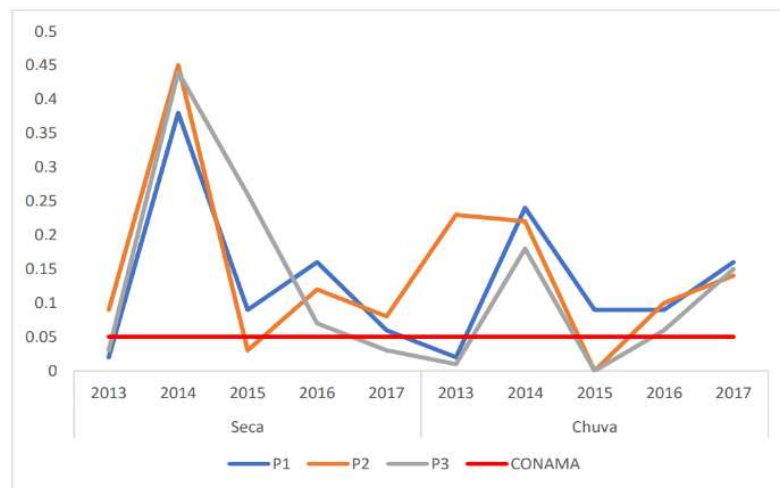

Figura 10: Variações do fósforo dos pontos amostrais nas campanhas dos períodos de seca e chuva durante os anos de 2013 a 2017, no reservatório da PCH Boa Sorte.

A importância do nitrogênio nos ecossistemas aquáticos se deve principalmente à sua participação na formação de proteínas, um dos componentes básicos da biomassa. Quando presente em baixas concentrações, esse nutriente pode limitar a produção primária. Dentre as diferentes formas, o nitrato, acompanhado do íon amônio, assume grande importância nos ecossistemas aquáticos, representando as principais fontes de nitrogênio para os produtores primários. Em águas bem oxigenadas, o nitrato (NO3) é a forma dominantes de nitrogênio inorgânico. Geralmente, a absorção preferencial de NH4+ pelas plantas contribui para as baixas concentrações dessa forma de nitrogênio. Altas concentrações de $\mathrm{NH} 4+$ na superfície de lagos e reservatórios (com baixas concentrações de substâncias húmicas) podem, portanto, ser atribuídas à influência de fontes pontuais e/ou difusas. Altas concentrações de $\mathrm{N}$-amoniacal nas regiões profundas dos reservatórios que inundaram grandes quantidades de biomassa vegetal podem ser o resultado do processo de decomposição. Por outro lado, em águas com baixa concentração de oxigênio, o nitrato é reduzido a nitrito. Assim, altas concentrações dessa forma de nitrogênio podem indicar lançamentos de efluentes domésticos (ESTEVES, 2011).

Na piscicultura intensiva, uma das principais fontes de compostos nitrogenados incorporados à água são os alimentos. No meio aquático o nitrogênio é encontrado na forma de amônia, nitrito e nitrato e pode determinar a produtividade do sistema (TAVARES, 1998).

No reservatório da PCH Boa Sorte, foram avaliadas as formas de nitrogênio (Amônia, Nitrito, Nitrato) e concluiu-se que os parâmetros não variaram significativamente entre os períodos de amostragem e entre 
os pontos amostrais. Os parâmetros estão de acordo com o estabelecido pela Resolução Conama 357/2005 (Nitrogênio Amoniacal 3,87 mg.L $\mathrm{L}^{-1}$ de N; Nitrito $1 \mathrm{mg} \cdot \mathrm{L}^{-1} \mathrm{de} \mathrm{N}$; e Nitrato $10,0 \mathrm{mg} \cdot \mathrm{L}^{-1} \mathrm{de} \mathrm{N}$ ).

A concentração de nitrogênio amoniacal no reservatório da $\mathrm{PCH}$ Boa Sorte variou de $0,00 \mathrm{mg} \cdot \mathrm{L}^{-1}$ (P2 e P3 em dezembro de 2015) a 0,17 mg. $\mathrm{L}^{-1}$ (P3 em maio de 2013). A concentração de nitrito foi de $0,00 \mathrm{mg} \cdot \mathrm{L}^{-}$ ${ }^{1}$ a $0,008 \mathrm{mg} \cdot \mathrm{L}^{-1}$ (P2 em dezembro de 2015). O nitrato apresentou concentrações entre $0,00 \mathrm{mg} \cdot \mathrm{L}^{-1}$ e 2,10 mg. $\mathrm{L}^{-1}$ (P3 em junho de 2014) (Figuras 11). É pertinente ressaltar que alguns meses do período experimental, os valores ficaram abaixo dos limites de detecção do equipamento.

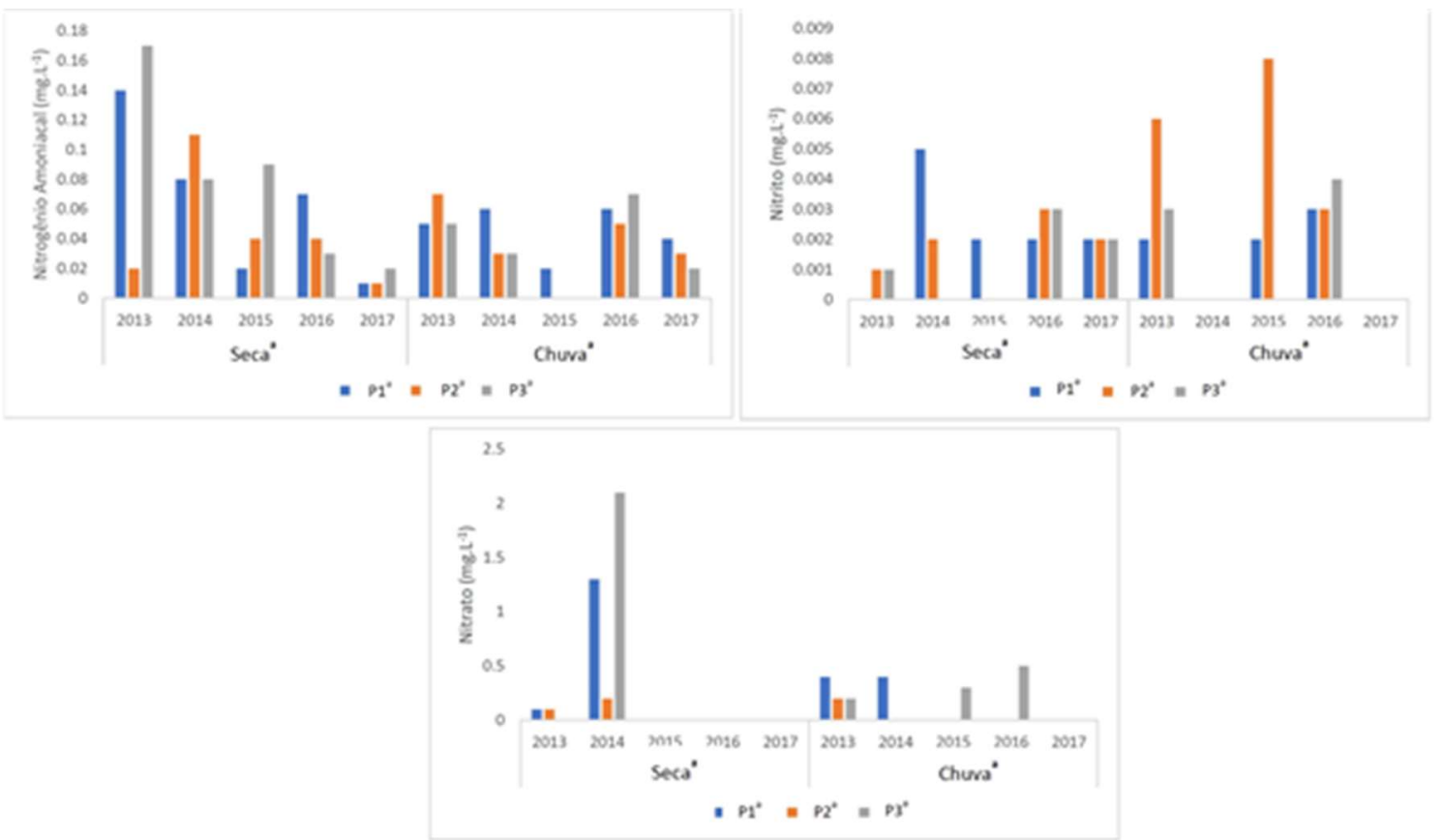

Figura 11: Variações do nitrogênio amoniacal, nitrito e nitrato dos pontos amostrais nas campanhas dos períodos de seca e chuva durante os anos de 2013 a 2017, no reservatório da PCH Boa Sorte.

\section{Capacidade de suporte}

A concentração média de fósforo total encontrado no reservatório da PCH Boa Sorte foi de $0,13 \mathrm{mg} \cdot \mathrm{L}^{-}$ ${ }^{1}$, ou seja, não atende o limite preconizado pela Resolução 357 do CONAMA (2005), que é de no máximo 0,05 mg.L-1 para águas de Classe 2, não sendo possível calcular a carga máxima de fósforo que poderia ser lançada no reservatório pela atividade de cultivo de peixes em tanques-rede. Portanto, o reservatório da PCH Boa Sorte não pode ser destinado a prática da piscicultura, pois poderá acarretar no aumento da concentração de nutrientes na água, o que poderá agravar o processo de eutrofização do reservatório.

Assumindo que a concentração média de fósforo durante o período de estudo (PI) é de $0,13 \mathrm{mg} \cdot \mathrm{L}^{-1} \mathrm{e}$ que a concentração média desejada (PF) após a implantação da piscicultura é de 0,05 mg. $\mathrm{L}^{-1}$, tem-se: $\Delta \mathrm{P}=-$ $0,08 \mathrm{mg} \cdot \mathrm{L}^{-1}$. Este valor de $\triangle \mathrm{P}$ demonstra que a capacidade de suporte do reservatório da PCH Boa Sorte já foi ultrapassada, visto que partiu de um valor negativo. O fósforo é considerado um dos nutrientes mais importantes para a determinação da biomassa fitoplanctônica e da qualidade da água em lagos tropicais e subtropicais (ATTAYDE et al., 1999). No entanto, os reservatórios são distintos dos lagos naturais, onde a dinâmica limnológica pode não ser semelhante e as respostas dos sistemas ao enriquecimento de nutrientes podem ser diferentes (WETZEL, 1993; TUNDISI et al., 1990). 
O tempo de residência da água nos reservatórios pode contribuir positivamente para a minimização do processo de eutrofização, principalmente em reservatórios que possuem um tempo pequeno de residência curto, ou seja, há uma maior renovação da água. No entanto, essa minimização da eutrofização com a renovação da água não favorece todos os reservatórios, uma vez que outros fatores influenciam diretamente esses corpos hídricos, como a presença de afluentes que contribuem para a carga de nutrientes em períodos chuvosos e ou reservatórios com baixa renovação de água. O reservatório da PCH Boa Sorte possui um tempo médio de residência de 14,69 dias conforme cálculos realizados neste estudo (Tabela 2), ou seja, neste período toda a água do reservatório é renovada, fato que ainda não foi capaz de contribuir para a redução das concentrações de fósforo no reservatório.

\section{CONCLUSÕES}

A implantação de parques aquícolas pode causar, por meio da produção de peixes, impactos na qualidade da água. A seleção de áreas favoráveis à implantação de tanques-rede, a caracterização limnológica e a determinação da capacidade de suporte do reservatório em que a piscicultura será implantada, podem contribuir para a tomada de decisão quanto à implantação do parque aquícola e nortear o órgão ambiental durante o processo de licenciamento, reduzindo assim os impactos ambientais que a atividade pode causar ao corpo hídrico, aumentando a possibilidade de mitigação.

No reservatório da PCH Boa Sorte, foram identificados 141 hectares de lâmina d'água com aspectos físicos e biológicos favoráveis à implantação dos tanques-rede. Com exceção do fósforo, os parâmetros limnológicos estão dentro do recomendado pela resolução CONAMA n 357 de 2005, em todos os pontos amostrais. Devido ao fósforo estar acima do recomendado pela legislação e a capacidade de suporte do reservatório da PCH Boa Sorte já ter sido excedida, o cultivo de peixes em tanques-rede no reservatório da PCH Boa Sorte não é recomendado.

A identificação das possíveis fontes que estão aportando concentrações de fósforo ao reservatório da PCH Boa Sorte e a posterior implementação de medidas para mitigar essas concentrações, dentro dos limites estabelecidos, é fundamental para que no futuro o reservatório possa ser explorado para a atividade de piscicultura.

\section{REFERÊNCIAS}

ANEEL. Agência Nacional de Energia Elétrica do Brasil. Atlas de energia elétrica do Brasil. Brasília: ANEEL, 2002.

APHA. American Public Health Association. Standard methods for the examination of water and wastewater. 21 ed. New York: American Public Health Association, 2005.

ATTAYDE, J. L.; BOZELLI, R. L.. Environmental heterogeneity patterns and predictive models of chlorophyll a in a Brazilian coastal lagoon. Hydrobiologia, v.390, n.1-3, p.129-139, 1999. DOI: https://doi.org/10.1023/A:1003546810358

BAKER, M. J.; BLOWES, D. W.; PTACEK, C. J.. Laboratory Development of Permeable Reactive Mixtures for the
Removal of Phosphorus from Onsite Wastewater Disposal Systems. Environmental Science \& Technology, v.32, n.15, p.2308-2316, 1998. DOI: https://doi.org/10.1021/es970934w

BEVERIDGE, M. C. M.. Cage and pen fish farming. Cairryng capacity models and evironmental impact. FAO Doc. Tech. Peches. Rome: FAO, 1984.

BOYD, C. E.. Water quality management for pond fish culture. Amsterdam: Elsevier, 1982.

BRASIL. Resolução CONAMA No 357, de 17 de março de 2005. Dispõe sobre a classificação dos corpos de água e 
diretrizes ambientais para o seu enquadramento, bem como estabelece as condições e padrões de lançamento de efluentes, e dá outras providências. Brasília: MMA, 2005.

CARNEIRO, P. C. F.; URBINATI, E. C.. "Stress" e Crescimento de peixes em piscicultura intensiva. In: SIMPÓSIO SOBRE MANEJO E NUTRIÇÃO DE PEIXES, 3. Anais Campinas: CBNA, 1999.

DAMASCENO, L. M. A. C.. Contribuição à caracterização limnológica da coluna d'água do reservatório da UHE - Luís Eduardo Magalhães em escala sazonal e diuturna. Monografia (Bacharelado em Engenharia Ambiental) Universidade Federal do Tocantins, Palmas, 2008.

DANTAS, M. C.; ATTAYDES, J. L.. Nitrogen and phosphorus content of some temperate and tropical freshwater fishes. Journal of Fish Biology, v.70, p.100-108, 2007. DOI: https://doi.org/10.1111/j.1095-8649.2006.01277.x

DILLON, P. J.; RIGLER, F. H.. A test of a simple nutrient budget model predicting the phosphorous concentration in a lake water. Journal of the Fisheries Research Board of Canada, v.31, n.11, p.1771- 1778, 1974. DOI: https://doi.org/10.1139/f74-225

ESTEVES, F. A.. Fundamentos de Limnologia. 3. ed. Rio de Janeiro: Interciência. 2011.

ESTEVES, F. A.. Fundamentos de Limnologia. Rio de Janeiro: Interciência, 1998.

FROSSARD, E.; BAUER, J. P.; LOTHE, F.. Evidence of vivianite in FeSO4-flocculated sludges. Water Research, v.31, n.10, p.2449-2454, 1997.

GUTTMAN, L.. Some necessary conditions for commonfactor analysis. Psychometrika, v.19, n.2, p.149-161, 1954. DOI: https://doi.org/10.1007/BF02289162

KAISER, H. F.. The varimax criterion for analytic rotation in factor analysis. Psychometrika, v.23, n.3, p.187-200, 1958.

KÖPPEN, W.. Climatología Tradicional. Fondo de cultura económica. Ciudad de México D. F., 1948.

KÖRNER, S.; VERMAAT, J. E.. The relative importance of Lemna gibba L., bacteria and algae for the nitrogen and phosphorus removal in duckweed-covered domestic wastewater. Water Research, v.32, n.12, p.3651-3661, 1998. DOI: https://doi.org/10.1016/S0043-1354(98)00166-3

KUBITZA, F.. Tanques-rede, rações e impacto ambiental. Revista Panorama da Aquicultura, v.51, p.44-50, 1999.

LANDA, G. G.. Composição do zooplâncton em quatro represas no Campus da Universidade Federal de Lavras: um subsídio à piscicultura. Dissertação (Mestrado em Zootecnia) - Universidade Federal de Lavras, Lavras, 1999.

MÃMAR, R. M.; CYRINO, J. E.. Piscicultura. Campinas: CATI, 1986.

MORIYAMA, K.; KOJIMA, T.; MINAWA, Y.; MATSUMOTO, S.; NAKAMACHI, K.. Development of artificial seed crystal for crystallization of calcium phosphate. Environmental Technology, v.22, n.11, p.1245-1252, 2001. DOI: https://doi.org/10.1080/09593330.2001.9619163

NEGADOMI, H.; KITAMURA, T.; WATANABE, M.; SASAKI, K.. Simultaneous removal of chemical oxygen demand (COD), phosphate, nitrate and $\mathrm{H} 2 \mathrm{~S}$ in the synthetic sewage wastewater using porous ceramic immobilized photosynthetic bacteria. Biotechnology Letters, v.22, p.1369-1374, 2000. DOI:

https://doi.org/10.1023/A:1005688229783

NIMER, E.. Climatologia no Brasil. Rio de Janeiro: Instituto Brasileiro de Geografia e Estatística, Superintendência de Recursos Naturais e Meio Ambiente, 1979.

PANTANO, G.; MAZZEO, D. E. C.; ROCHA, T. H. S.; MARINMORALES, M. A.; FADINI, P. S.; MOZETO, A. A.. Toxicity of the sawdust used for phosphorus recovery in a eutrophic reservoir: experiments with Lactuca sativa and Allium cepa. Environmental Science and Pollution Research, v.1, p.1, 2021. DOI:https://doi.org/10.1007/s11356-020-11868-9

PANTANO, G.; SOUZA, T. C. R.; PEREIRA-FILHO, E. R.; FADINI, P. S.; MOZETO, A. A.. Remediation of Eutrophic Aquatic Ecosystems: Evaluation of Phosphorus Adsorption by Sawdust. Integrated Environmental Assessment and Management, v.1, p.1-12, 2019. DOI: https://doi.org/10.1002/ieam.4184

PEDROZA FILHO, M. X.; BARROSO, R. M.; FLORES, R. M. V.. Diagnóstico da cadeia produtiva da piscicultura no estado de Tocantins. Palmas: Embrapa Pesca e Aquicultura, Boletim de Pesquisa e Desenvolvimento, 2014. p.1-66.

QUEVEDO, C. M. G.; PAGANINI, W. S.. Impactos das atividades humanas sobre a dinâmica do fósforo no meio ambiente e seus reflexos na saúde pública. Ciência \& Saúde Coletiva, v.6, n.8, p.3529-3539, 2011. DOI: https://doi.org/10.1590/S1413-81232011000900021

ROY, P. K.; LALL, S. P.. Dietary phosphorus requirement of juvenile haddock (Melanogrammus aeglefinus L.). Aquaculture, v.221, p.451-468, 2003. DOI: https://doi.org/10.1016/S0044-8486(03)00065-6

SANTOS, I.; FILL, H. D.; SUGAI, M. R. V.; BUBA, H.; KISHI, R. T.; MARONE, E.; LAUTERT, L. C.. Hidrometria aplicada. Curitiba: Instituto de Tecnologia para o Desenvolvimento, 2001.

SCHMITTOU, H. R.. High density fish culture in low volume cages. Singapura: American Soybean Association, 1993.

SCHULTER, E. P.; VIEIRA FILHO, J. E. R.. Evolução da piscicultura no Brasil: diagnóstico e desenvolvimento da cadeia produtiva de tilápia. Rio de Janeiro: IPEA, 2017. p.143.

SEAGRO. Situação atual da aquicultura tocantinense. Palmas: SEAGRO, 2017.

SEPLAN. Atlas do Tocantins: Subsídios ao Planejamento da Gestão Territorial. Palmas: SEPLAN, 2012.

SOUZA, M. J. M.; ROCHA, A. J. A.. Areias river (Goiás, Brasil): Assessment to the water with view to use in supplying the Federal District. In: SIMPÓSIO SOBRE O CERRADO, 8. Anais. 1996. 
SOUZA, F. H. M.; VIOLA, M. R.; AVANZI, J. C.; GIONGO, M.; FILHO, M. V.. Thornthwaite's Climate Regionalization for the State of Tocantins, Brazil. Floresta, v.49, n.4, p.783-792, 2019. DOI: http://doi.org/10.5380/rf.v49 i4.59188

SUBASINGHE, R.; SOTO, D.; JIA, J.. Global aquaculture and its role in sustainable development. Reviews in Aquaculture, v.1, p.2-9. 2009. DOI: https://doi.org/10.1111/j.17535131.2008.01002.x

TAVARES, L. H. S.. Limnologia dos sistemas de cultivo. In: VALENTI, W. C.. Carcinicultura de água doce: Tecnologia para a produção de camarões. Brasília: FAPESP, 1998. p.4775.

TUNDISI, J. G.; MATSUMURA-TUNDISI, T.; CALIJURI, M. C.. Limnology and management of reservoirs in Brazil. In: STRASKRABA, M.; TUNDISI, J. G.; DUNCAN, A.. Comparative limnology and water quality management. Dordrecht: Kluwer Academic Publishers, 1993, p.25-55.
VIEIRA, E. M.. Contribuição metodológica para a préidentificação de áreas adequadas à implantação de parques aquícolas no reservatório de nova ponte - Minas Gerais. Tese (Doutorado em Engenharia Civil) - Universidade Federal de Viçosa, 2009.

VOLTOLINA, D.; CORDERO, B.; NIEVES, M.; SOTO, L. P. Growth of Scenedesmus sp.in artificial wastewater. Bioresource Technology, v.68, n.3, p.265-268, 1999. DOI: https://doi.org/10.1016/S0960-8524(98)00150-3

WEATHERLEY, A. H.; GILL, H. S.. The biology of fish growth. Orlando: Academic Press, 1987.

WEBBER, D. C.; MATOS, F. T.; OLIVEIRA, F. M. M.; UMMUS, M. E.. Manual Técnico para Seleção de Áreas Aquícolas em Águas da União. Palmas: Embrapa Pesca e Aquicultura, 2015.

WETZEL, R. G.. Limnologia. Lisboa: Fundação Calouste Gulbenkian, 1993.

A CBPC - Companhia Brasileira de Produção Científica (CNPJ: 11.221.422/0001-03) detém os direitos materiais desta publicação. Os direitos referem-se à publicação do trabalho em qualquer parte do mundo, incluindo os direitos às renovações, expansões e disseminações da contribuição, bem como outros direitos subsidiários. Todos os trabalhos publicados eletronicamente poderão posteriormente ser publicados em coletâneas impressas sob coordenação da Sustenere Publishing, da Companhia Brasileira de Produção Científica e seus parceiros autorizados. Os (as) autores (as) preservam os direitos autorais, mas não têm permissão para a publicação da contribuição em outro meio, impresso ou digital, em português ou em tradução. 